This item was submitted to Loughborough's Research Repository by the author.

Items in Figshare are protected by copyright, with all rights reserved, unless otherwise indicated.

\title{
The role, benefits and selection of sport psychology consultants: Perceptions of youth-sport coaches and parents
}

PLEASE CITE THE PUBLISHED VERSION

https://doi.org/10.1016/j.psychsport.2017.12.001

\section{PUBLISHER}

(C) Elsevier

VERSION

AM (Accepted Manuscript)

\section{PUBLISHER STATEMENT}

This work is made available according to the conditions of the Creative Commons Attribution-NonCommercialNoDerivatives 4.0 International (CC BY-NC-ND 4.0) licence. Full details of this licence are available at: https://creativecommons.org/licenses/by-nc-nd/4.0/

\section{LICENCE}

CC BY-NC-ND 4.0

\section{REPOSITORY RECORD}

Thelwell, Richard C., Jade Wood, Chris G. Harwood, Toby H. Woolway, and Judy L. van Raalte. 2019. "The Role, Benefits and Selection of Sport Psychology Consultants: Perceptions of Youth-sport Coaches and Parents". figshare. https://hdl.handle.net/2134/28003. 


\section{FINAL ACCEPTED VERSION:}

Thelwell, R.C., Wood, J., Harwood, C., Woolway, T., \& van Raalte, J. (2017). The role, benefits, and selection of sport psychology consultants: Perceptions of coaches and parents. Psychology of Sport and Exercise.

doi.org/10.1016/j.psychsport.2017.12.001

Accepted on: $1^{\text {st }}$ December 2017

Running Head: The role, benefits and selection

The role, benefits and selection of sport psychology consultants: Perceptions of youth-sport coaches and parents

Revision submitted: November 2017 
Abstract

2 Objectives: With practitioners needing to be 'more things to more people', it is essential to

3 understand third-party consumer perceptions of the role and benefits of sport psychology

4 consultants (SPC), and the characteristics that may influence such services being sought.

5 Design: A qualitative thematic analysis approach was used in Study 1 and a cross-sectional conjoint

6 analysis approach was employed in Study 2.

7 Methods: In Study 1, 22 participants (11 youth-sport coaches, 11 parents) took part in semi-

8 structured interviews to investigate, a) understanding the SPC role, b) the benefits of seeking the

9 services of an SPC, and, c) the salient characteristics of an SPC that would influence judgments on

10 preference and likelihood to seek consultant services on behalf of their athlete/child. In Study 2, a

11 total of 115 participants (51 youth-sport coaches, 64 parents) rated 32 practitioner profiles

12 generated from Study 1, with a conjoint analysis employed to determine the relative importance of

13 SPC characteristics.

14 Results: SPCs were viewed by youth-sport coaches and parents as practitioners who can help

15 athletes enhance their performance and well-being, which would be of benefit to athletes. The SPC

16 attribute most important to coaches and parents was interpersonal skills, with a preferred SPC

17 profile also including a high level of experience and training, and a known reputation.

18 Conclusions: SPCs are viewed by youth-sport coaches and parents as experts regarding

19 performance enhancement and well-being. SPCs with strong interpersonal skills, extensive

20 experience and training, and a known reputation are preferred by coaches and parents. Findings

21 reinforce the importance of educating those responsible for the ongoing development of athletes to

22 the role and benefits of SPCs, and for SPC training to ensure that interpersonal skills development

23 opportunities are available.

25 Key words: applied sport psychology, consultant roles, consumer preference, professional training 
1 The role, benefits and selection of sport psychology consultants: Perceptions of youth-sport coaches and parents

With the increased focus on quality assurance procedures associated with the practice of sport and exercise psychology consultants (SPC), researchers have attempted to gain a more detailed insight to: a) the development of appropriate training and supervision programmes for SPCs (Eubank, 2016), b) characteristics associated with effective practitioners (Lovell, Parker, Brady, Cotterill, \& Howatson, 2011), and, c) the processes associated with gaining entry to consult with clients (Hamberger \& Iso-Ahola, 2006). Researchers have also explored the selection of SPCs (Morris, Alfermann, Lintunen, \& Hall, 2003) and marketing of SPCs to potential client groups (Woolway \& Harwood, 2015). Additional research that explores perceptions of SPCs from the point of view of coaches, and in particular, youth-sport coaches and parents may be valuable. Following initial qualitative work, researchers have empirically examined the perceived characteristics of effective SPCs (e.g., Lubker, Watson, Visek, \& Geer, 2005) with Lubker, Visek, Watson, and Singpurwalla, (2012) using conjoint analysis to determine the relative importance of the characteristics of effective SPCs in relation to each other. In attempting to understand why 'potential clients’ make one choice over another, sport psychologist profiles from combinations of eight attributes (gender, race, interpersonal skills, body build, attire, athletic background, professional status, sport knowledge) were combined to create 'sport psychologist profiles' with the results from the 464 college athletes suggesting professional status to be the most influential attribute (23\%), followed jointly by athletic background and interpersonal skills (14\%), then sport knowledge and attire (12\%). With regard to professional titles, Van Raalte, Brewer, Matheson, and Brewer (1996) found that the professional title 'sport psychologist' was perceived as a non-sport profession. Apparently, the term "sport" had little impact on modifying perceptions of the title 'sport psychologist' as a psychological one, although it should be noted that Maniar, Curry, Sommers-Flanagan, and Walsh (2001) found the inclusion of the term 'sport' in the title 'sport psychologist' enhanced individual's willingness to access services. Further exploration of the 
1 effects of SPC credentials by Lubker et al. (2012) indicated SPCs described as having an advanced

2 degree as being preferred to those without any credentials.

To combine the analysis of credentials and titles whilst also investigating whether education

4 about the use of titles and associated credentials impacts consumer attitudes and preferences for

5 consultants, Woolway and Harwood (2015) examined perceptions of three professional titles (sport

6 psychologist, life coach, and neuro-linguistic programming), a range of other practitioner

7 characteristics, and the extent to which a brief intervention impacted these preferences. Such titles,

8 whilst reflecting clear differences in terms of training and accreditation requirements, are frequently

9 sought after within the sporting domain. Having been asked to provide preferences of the three

10 professions, the athlete participants were then provided with short educational vignettes designed to

11 enhance understanding to what the professions were, and the training requirements for each. Using

12 conjoint analysis to assess the relative importance of practitioner attributes pre- and post-

13 intervention, interpersonal skills emerged as the most important attribute prior to intervention,

14 irrespective of professional title. However, post-intervention an increased salience in professional

15 title was reported. Collectively, the findings reinforce the importance for SPCs, and the broader

16 applied sport psychology community to educate consumers with the requisite information to their

17 education, training, credentials and roles to ensure they are approached by those seeking sport

18 psychology support, as opposed to alternative professions that may be less appropriate.

Although the literature presented thus far has contributed a great deal to consumer perceptions of SPC effectiveness, it is reasonable to assume that the information does not fully

21 reflect the way athletes engage in consultation with SPCs. This is despite such interest dating back

22 to the 1990s where, upon the emergence of sport psychology services, Taylor (1994) provided

23 insightful commentary to the ethical issues associated to the use of the term 'sport psychologist',

24 and offered guidance to how practitioners should operate within their competence boundaries. As

25 such, it is reasonable to suggest that the reality for many athletes is that the selection of an SPC is

26 influenced by other gatekeepers who operate within the sporting environment and at a youth level; 
1 coaches and parents. Such a view reinforces recent suggestions that parent and coach behaviours

2 influence, for example, athlete decision-making and motivational orientation within youth-sport

3 contexts (Keegan, Harwood, Spray, \& Lavellee, 2014; Knight, Berrow, \& Harwood, 2017).

On this point, researchers have examined the perception held of SPCs by coaches, and their

5 intentions to use such services. For example, in their survey of NCAA Division 1 coaches,

6 Wrisberg, Loberg, Simpson, Withycombe, and Reed (2010) reported most coaches as willing to

7 encourage their athletes to seek support from an SPC. However, although coaches favoured the role

8 of an SPC to be full-time, less than half of those sampled supported the view that SPCs should be

9 present in training and competition environments. Further to this, Zakrajsek and colleagues have

10 completed a programme of work examining the perceptions, preferred use, and perceived benefits

11 of SPCs from the perspective of NCAA Division 1 coaches and athletic trainers. In their initial

12 work, Zakrajsek, Martin, and Zizzi, (2011) reported high school football coaches who were

13 confident in, and open to engaging with the outcomes of working with an SPC, to be more likely to

14 consider recommending the use of an SPC. Elaborating on this further, Zakrajsek, Steinfelt, Bodey,

Martin, and Zizzi (2013) examined NCAA Division 1 coaches’ perceptions and use of SPC services with key outcomes focusing on the importance of the SPC and coach to be on the 'same page', and the degree to which the SPC can meet the coach expectations; who they are (e.g., experience), what they do (e.g., provide value), and how they do it (e.g., accessibility). In the first of two studies involving NCAA Division 1 Athletic Trainers, Zakrajsek, Fisher, and Martin (2016) reported an inability of more than $50 \%$ to describe sport psychology, with those who could, perceiving it as a mental tool primarily focused on performance enhancement. In a final study, Zakrejsek, Martin, and Wrisberg (2016) reported athletic trainers with positive experiences of working with SPCs to be more likely to seek the services of such individuals to assist with the injury-rehabilitation process, and view the benefits of SPCs in a more favourable light. What is obvious from the aforementioned studies is the focus on coach perceptions of SPCs and the absence of parental experiences and perceptions of SPCs, despite their key role in youth-sport. 
Despite the advances about how coaches perceive, and use, SPCs, less is known about how

2 this takes places within a youth-sport environment, or indeed, about how parents perceive SPCs.

3 This is despite some preliminary insight from researchers who have provided commentary to how

4 parents and coaches may play an influential role in the delivery of sport psychology (e.g., youth

5 sport consulting model; Visek, Harris, \& Blom, 2009). With the above in mind, it is reasonable to

6 suggest that although an emerging knowledge base demonstrating how SPCs can inform athlete

7 consumers exists, little is known about how youth-sport coaches and parents perceive SPCs.

The current work used a mixed-methods approach across two unique, yet inter-related study

9 parts to gain a more detailed insight to gatekeeper perceptions of SPCs. Given the overarching research question to elicit gatekeeper perceptions to SPCs, study 1 used a qualitative approach with subsequent thematic analysis, designed to elicit from youth-sport coaches and parents how they describe SPCs in terms of a) understanding the SPC role, b) the benefits of seeking the services of an SPC, and, c) the salient characteristics of an SPC that would influence judgments on preference and likelihood to seek consultant services on behalf of their athlete/child. The goal here of the final part being to generate SPC profiles based on gatekeeper insights. To understand gatekeeper perceptions of SPCs across a broader sample, the second study used a quantitative conjoint analysis to examine the SPC profiles generated from Study 1, and to identify the relative value related to aspects of the descriptions.

\section{Study 1 - Method}

\section{Participants}

A total of 22 participants (11 youth-sport coaches and 11 parents) were recruited for the study. All coaches (male $=10$, female $=1 ; M$ age $=36.1, S D=11.2$ ) were full-time coaches (minimum 2 years) of team (cricket, $n=5$; football, $n=2$ ) or individual sports (athletics, $n=1$; boxing, $n=1$; tennis, $n=2$ ). The parents (male $=8$, female $=3$; $M$ age $=47.5, S D=5.7$ ) had children who were involved in either team (cricket, $n=2$; football, $n=3$ ) or individual sports (boxing, $n=4$; tennis, $n=2$ ) at a level where they were within a professional organisation (e.g., 
1 academy level) or national governing body (e.g., youth national structure). Participants were only

2 eligible for participation in the study if they had no previous experience of using SPC services.

\section{Data Collection}

Interview guide. An interview guide was developed by members of the research team who held more than 75 years of combined experience and were Health and Care Professions Council Registered Sport and Exercise Psychologists and/or British Association of Sport and Exercise Science Accredited Sport and Exercise Scientists and/or Association for Applied Sport Psychology Certified Consultants. The interview guide was developed following a review of the literature that examined consumer preferences of SPCs, knowledge of SPCs, and SPC attributes. The guide was initially pilot tested with two individuals (1 youth-sport coach and 1 parent) who met the criteria for full study involvement prior to the data collection period commencing. The pilot interviews enabled minor amendments to the clarity of some questions to be made and demonstrated the need for inclusion of further elaboration and clarification probes.

The final interview guide consisted of three sections: the role of SPCs (e.g., "what is your understanding to the role of a sport psychologist?”), perceptions of how an SPC would benefit their athlete/child (e.g., “how would a sport psychologist help your athlete/child?”), and, characteristics that influence the selection of an SPC (e.g., "what are the characteristics you would expect an SPC to possess for you to approve their work with your athlete/child?”). A social validation process was also employed to check the interview process with regard to whether participants felt they could tell their story fully, whether their responses were influenced, and to ensure that opportunities to provide comments or suggestions about the procedure and format were available.

Procedure. Following an initial recruitment campaign where sporting organizations known to the first two researchers were contacted, subsequent snowballing recruitment took place where potential participants were asked to contact one of the research team to confirm their interest. Having had the study purposes explained, all participants volunteered their consent prior to taking part. The research was undertaken according to the ethical guidelines of the lead author's 
1 institution, from which ethical clearance was received. Prior to each interview, participants were

2 provided with an information sheet outlining the general areas for discussion. All interviews were

3 face-to-face and conducted by the same researcher who had received training in qualitative

4 techniques. Despite the semi-structured interview format enabling a certain element of structure to

5 each interview, the ordering of questions and subsequent exploration varied depending on

6 participant responses. To supplement the 'fixed' questions across the interviews, probe ("please can

7 you elaborate on [the issue]?”) and elaboration (“could you explain [the issue] in more detail

8 please?”) questions were employed to facilitate the flow of the interviews. At the conclusion of

9 each section of the semi-structured interviews, participants were asked if all appropriate responses

10 had been discussed and explored in their entirety. Interviews lasted $48-73 \mathrm{~min}(M$ coach length $=$

$1158.32, S D=9.44 ; M$ parent length $=52.24, S D=7.91$ ), were recorded digitally, and yielded a total

12 of 138 pages $($ coach $=71$; parents $=67)$ of single-spaced text having been transcribed verbatim.

\section{Data Analysis}

In keeping with the post-positivist approach to the data collection and adhering to previous

literature (e.g., Schinke, McGannon, Batocchio, \& Wells, 2013), we employed the six steps proposed by Braun and Clarke (2006) to conduct an interpretive thematic analysis. To commence the process, data were transcribed verbatim prior to the first and second authors reading, and rereading transcripts to familiarize themselves with the content. At this point, a reflective segment was utilized to record initial impressions and note similarities and differences. This was especially important given that the coach and parent data were analysed separately, and only combined for the purposes of reporting. The second stage required the identification of key features in a systematic manner using codes across each data set. Completion of this enabled the third stage to take place where two authors met and discussed their preliminary codes and collated interpretations into further themes. The fourth stage was where the coded data were developed into a thematic map, where the two authors considered the alignment of themes and sub-themes. Across stages two to four, the researchers used an iterative process to place the raw data themes in lower, then higher 
1 order themes that were organised into general dimensions. To refine each theme, the fifth stage

2 enabled the development of clear definitions to be derived for each label. In keeping with the

3 purposes of thematic analysis, the final step afforded the opportunity for selected data extracts to be

4 collated for presentation. Throughout the process, the two authors tried to ensure that they were

5 being reflexive and interactive with the data, and using the recommendations forwarded by Smith

6 and McGannon (2017) they worked as critical friends in a reflexive manner. In the latter stages of

7 the data analysis the themes were deductively placed into post hoc general dimensions, based on the

8 emerging themes prior to the third author becoming involved to ensure that appropriate member

9 reflections on the data had taken place between the first and second authors.

\section{Results}

The results derived from the data analysis procedures represent the interview responses from the coach and parent populations. For both populations, the raw data themes were organized into lower, and then higher order categories prior to being placed within the three key dimensions of the research foci: a) the role of practitioner psychologists; b) views to how working with an SPC would benefit their athlete/child; and c) characteristics that influence the selection of a practitioner. For purposes of brevity, the data are presented via verbatim quotations with the specific data being presented for the three study aims in figures 1-3.

\section{The role of SPCs}

For coaches, a total of 68 raw themes were inductively placed into 15 lower order themes and 3 higher order themes (practitioner role, delivery mode, availability). For parents, the 54 raw data themes were placed into 14 lower order themes prior to being placed into the same higher order themes to those identified for the coach data.

One common perceived practitioner role discussed by coaches and parents related to 'athlete performance' with specific raw data themes relating to athletes being able to fulfil their potential, gain confidence, and manage pressure during performance. Specifically, one coach illustrated the role of an SPC as helping athletes to be more successful: 
"I suppose the key role is to help them improve their performance to be, well, more successful. I want them to support [the athletes] and help them deal with the pressures. We get them in to help with getting them better and to be more aware to what they have to face in [sport]...they need to skills to be successful when it really matters”.

A further perceived practitioner role raised by coaches and parents was the contribution made to athlete development and well-being. Along with 'helping athletes understand the demands of elite sport', and 'contribute to holistic development' one interesting theme emerging from the parents was to do with guidance on alternative careers. This is detailed in the following quote: "I get that there are performance benefits and all of that but the reality is that so few of them will make it, they have to have other options. I guess that I hope that they will give [child] information on what else is out there, what else they can do. They develop all these skills so hopefully they realize that they may not get there and that they may have to think about other jobs in the future. Even if they do make it, it won't see them through to when they're much older so they will have to have something to support them when they finish playing”. Another coach referred to the benefits of the support that practitioners afford them (e.g., feedback on communication methods), both coaches and parents acknowledged the need for practitioners to 'support other groups'. In fact, both groups commented on the importance of parental education with one theme cited by parents referring to the education that they receive to how they communicate with their children:

“There are times when I feel quite lonely as a parent. We take them around and watch them but it is hard to know what to say...they get back in the car and it's like, silent, coz I am unsure what to say. There are times when I could do with knowing what the best thing to say is? How can I support them when they have had a [poor performance], or what has [coach] said to them?” 
The second higher order theme reflecting the perceived roles of a practitioner reflected the

2 mode of delivery with coaches and parents suggesting support to be via individual, group, and

3 practical formats. This very point is captured by one of the coaches who commented "to be honest, I

4 want [SPC] to be effective, I don't mind how they work with [athletes] as long as they can link it

5 with what I do with them”. One of the interesting themes reflected the importance for SPC services

6 to be delivered within the training environment rather than just limited to the 'classroom'.

"There is certainly a need to meet with [athletes] and talk things through and at times, do the workshops to get key messages across but the best work, I think, is for them to come into [training environment] and to integrate their messages into the actual training. The [athletes] don’t always get the transfer bit, the skills into practice, so to have [practitioner] involved and actually leading the session is crucial. For me, if they can’t do it then they can't really be effective”. The final higher order theme reflected data that emerged in relation to availability. There were contrasting views to when, and where practitioners should be available but the consistent theme was that the practitioners should be available when the athlete requires them. As an advancement of this, there were also suggestions to the importance of remote electronic support with Skype and email as commented on by one of the parents:

“They [the child] know when things aren’t right and they don’t always need me or [coach] to say they need some help. I am happy that they can contact them in their own time and do Skype or something, they all have the phones and tablets so it isn’t strange for them...we know who they are working with so it is fine and [the sporting organization] are happy for it”.

\section{Benefits of working with an SPC}

A total of 68 raw data themes were reported by coaches and placed into 14 lower order themes prior to the two higher order themes labelled 'enhanced psychological strength' and 'elite standard awareness'. For parents, the analysis resulted in the accrual of 57 raw data themes prior to 
113 lower order themes, and then the same higher order themes as the coach data. One of the most

2 consistent themes across the coach and parent participants reflected the beneficial influence that

3 SPCs have towards enhancing athlete confidence, and more specifically to instilling a positive

4 attitude. This issue is captured in the following extract from one of the coaches: "They [the athletes] have so much to deal with and one mistake can be it, it can all just fall apart. I mean they have to be positive, they know they are gonna make mistakes coz that's the job we're are preparing them for. I mean at the end of the day, we try and prepare kids to play international sport, play sport in front of thousands of people. So yeah, they've gotta be positive and have the right attitude to deal with it all, and that's the stuff outside of [sport] too. I think a key job of the [SPC] is to help them learn how to deal with that stuff, to build the skills, and to make sure that they have confidence all the time, or know where to get it from”.

A further benefit to athletes working with SPCs reported by coaches and parents was the perceived development of athlete toughness and resilience. Themes reflecting the ability to cope with the wide-ranging sporting demands, managing performance downturns, and coping with pressure were cited across coach and parent groups. Parents also noted the need for athletes to cope with parental support. "Sometimes they go out there looking really timid, almost afraid of failure. The [SPC] can help them sort that and understand how to recover from the setbacks. They [child/ren] talk about not wanting to let us down and all that but so long as they do their best they won't. I feel [child] has to get over what they think we are thinking as we are really proud of them and [child] needs to toughen up and not worry about us. Hopefully they [SPC] can help them get that tough edge where they don’t feel any pressure from us. We've had our turn 
and it’s our choice to support [child] now. If it doesn’t work out they just have to know that we support them and they have done all they can”.

Two further interesting themes regarding enhanced psychological strength emerged from the parent data sets within the 'enhanced self-awareness' and 'understanding of others' lower order themes. First, it was the view of many parents that SPCs could help their children with trying to separate their sport from home life. In fact, one parent commented:

"They need to leave it behind, leave it at the door, they bring their anger, frustration and all that home with them and it can be a nightmare when they walk in, they need help to see how they behave and treat us sometimes...the [SPC] can help them channel it, leave it behind, help them with understanding the separation between home and sport. Don’t get me wrong, I know they are annoyed but they need to learn to manage it”.

A related theme referred to how the SPC was perceived to be able to enhance understanding of sibling relationships and the below was raised by one of the parents:

"My lot [children] are ultra-competitive and although they get on, it is a competition and I just wish that sometimes they could help each other. But then I know some others [families] and they have one who is totally nonsporty and they just don’t have anything to do together. I think they [SPC] can help with getting them to chill out a bit when they are together, they must use up so much energy when they go on together and sometimes just talking and helping each other, but someone else telling them to do it would help”.

The second higher order theme emerging from the perceived benefits associated with working with an SPC reflected an enhanced awareness of the standards needed to be able to develop to the elite level. One intriguing theme was mentioned by coaches and related to organizational expectations, and more specifically, to where the athlete sits within the organization as suggested in the following: 
"It's tough, there is a load of competition and we only sign a few every year to turn pro. They have to understand where they [child] sit within the bigger framework and what they have to do to progress... we tell them that all the time but having someone else give the same message, just a different voice can have just as much impact on them”.

A final theme, mentioned by both coaches and parents reflected the importance of the athletes having the awareness to make the most of their opportunities and trying to develop themselves at all times. One parent explains the benefit that an SPC can have in this regard in the following:

"We want them to give it a good go, to see how far they can push themselves and the [practitioner] can help with the motivating bit to keep them working. They have great opportunities here, all the support they could want and good examples of people who have been in their position and made it so they need to push themselves all the way”.

\section{Characteristics influencing the selection of an SPC}

A total of 64 raw data themes emerged from the coach data that were then placed into 21

lower order themes prior to six higher order themes (reputation, qualification, knowledge, experience, interpersonal skills, service nature). Parent responses yielded 49 raw data themes that were placed into 19 lower order themes prior to sharing the same higher order themes. Within the reputation higher order theme, although several consistent responses across the coach and parent participants were cited (e.g., recommendations), there were some contrasting views. For example, parents cited advertising as being a key characteristic, whereas coaches appeared to use their perceived knowledge of SPCs to influence the reputational judgment made. The responses in relation to qualifications were of interest in that coaches appeared to demonstrate knowledge of the importance of professional accreditation when selecting a practitioner, a perception that did not appear to be held, or at least mentioned, by parents. 
Further to the reputational and qualification based characteristics, parents and coaches

2 reported 'knowledge' and specifically 'sporting knowledge' and 'population knowledge' as key selection criteria. As such, within the population knowledge lower order theme, data referring to the SPCs ability to communicate with the population in question was raised. Although there were no suggestions to how this would be assessed, one parent made the following assertion: "One of the things I'd look for is how they get things over, these kids are switched on and they'll suss you out pretty quick. They need to know how to get things across, use the right language and make things exciting. If I were a [athlete] then I wouldn't want to sit around, I'd want to know why it will help and what it will do".

Closely aligned to having the requisite knowledge is the requirement to have experience. There were several data themes emerging to the differing levels of experience that coaches and parents would seek in an SPC. These included whether they had performance experience and coaching/parental experience. Amongst the more consistent themes was the extent of SPC experience expected. For example, one of the coaches commented "they have to be experienced...if I'm bringing them in I can't have people who have little or no experience, these [athletes] are the future and they have to have the right support”. Supporting this stance were many parental comments with the following being of relevance, "I would want them to be pretty well experienced, my [child] deserves someone who can give them the right support and has been around a while to pass the information on”.

Coaches and parents alike referred to the importance of interpersonal skills on several occasions with references made to communication, interpersonal style, and observable presentation. The most commonly cited themes were associated with interpersonal style and the need to be approachable, personable, able to listen, trustworthy, timely, and respected. For parents, a key interpersonal skill was in relation to communication, and more specifically to whether they themselves would feel comfortable in the practitioner's company. 
“If I couldn't work with them or feel comfortable with them then I won't have them, I need to know that I am ok with who [child] is working with. Even though I know where they are and what they are doing, I kinda want to sit in the first session, or at least part of it to see what they are like”.

A final theme worth noting referred to service nature, with one of the key higher order themes being the cost associated with the support. Although both coaches and parents referred to value for money, for coaches, many of the costs would be absorbed within their organization budgets. For parents, they would be more likely, although not always, to meet the costs of employing an SPC, although they were not fully able to articulate what costs they deemed appropriate:

"A key thing is how much they cost, is it worth it, what are they going to give for it, how do we know whether it is a good cost? I know you can't always tell how things will work out but you've gotta think of the value for money. Some people we know get it as part of the club but there are times when that isn't working and we go elsewhere”.

\section{Discussion - Study 1}

The aim of this study was to examine youth-sport coach, and parental understanding of the role of an SPC, the benefits of seeking the services of an SPC for their athlete/child, and the salient characteristics of an SPC that would influence judgements on preference and likelihood to seek SPC services for their athlete/child. To accomplish this goal a series of semi-structured interviews were conducted with youth-sport coaches and parents of team and individual sport athletes, with data analysed in accord with the principles of thematic analysis.

With reference to how youth-sport coaches and parents understand the role of an SPC, there are consistencies across the groups’ perceptions of the SPC role, and there are several stark contrasts. Both coaches and parents reported that they perceived SPCs to have an influence on athlete performance, as well as the enhancement of psychological strength, and enhanced awareness 
1 of elite standard expectations. However, when viewing the raw data themes, it was interesting to see

2 the extent to which parents perceived a key role of the SPC to be associated with athlete

3 development and well-being. This is not to say that coaches were not of the opinion that SPCs

4 should be utilized for broader development purposes, more a case that they were more focused on

5 the performance benefits that they anticipated would be realized following work with an SPC. A

6 further key observation is the extent to which coaches perceive the role of an SPC being to assist

7 them; both in terms of direct support, and for the coaches' continued development. In support of

8 recent commentaries (e.g., McCarthy \& Giges, 2017; Rynne, Mallett, \& Rabjohns, 2017) coaches

9 certainly perceive themselves as performers in their own right, and as such, see the SPC as a vehicle

10 to influence their performance capability. Parents also perceived the SPC role to include coach

11 support, as well as to develop parental knowledge of sport psychology (Harwood \& Knight, 2015).

12 Finally, in addition to some of the more outcome-focused roles, there were a number of key process

13 expectations that coaches, and parents held of SPCs. For example, there was a common perception

14 across both groups that the SPC should deliver services in varying formats and be easily available

15 to athletes. In fact, for the latter point, the availability of e-support was reinforced suggesting that,

16 perhaps, with ever-evolving social media usage, alternative formats of support require development

17 and training (Heaney, 2013).

The results of this research have important implications for the field of sport psychology.

Given the lack of clear understanding to the roles of SPCs, it could be valuable for individuals and organizations to disseminate more widely and clearly the benefits of SPCs and to further manage the expectations held by potential consumers, especially those with limited experience of utilizing such services. Of course, this has to an extent been encouraged in previous work (e.g., Woolway \& Harwood, 2015) but consideration to how SPCs are perceived by alternative gatekeepers such as parents and coaches appears necessary. When considering SPC training, findings associated with modes of delivery (e.g., individual, group, practical) and availability appear to warrant attention given that many training routes appear to solely focus on individual support. Training on how best 
1 to consult with both individuals and groups (be they athletes, coaches, parents, significant others)

2 seems necessary, as does increasing awareness of how best to consult within practical settings (e.g.,

3 Ponnusamy \& Grove, 2014) and when using alternative approaches such as social media (Cotterill

4 \& Symes, 2014). Given that the data were generated by potential consumers, those delivering the

5 services must be cognizant of the consumer demands.

Turning attention to the characteristics associated with influencing youth-sport coach and

7 parent judgments on preference and likelihood to seek SPC services, themes similar to those

8 reported in athlete studies emerged (e.g., interpersonal skills; Woolway \& Harwood, 2015), with the

9 exception of physical (e.g., build, weight) and uncontrollable (e.g., race, gender) characteristics.

However, some similarities to findings reported in previous coach-focused studies, and in particular that by Zakrajsek et al. (2013) where coaches expressed preferences to experience, desirable characteristics, and, style of communication of the SPC. Such findings reinforce some of the current findings given that for the population sampled, personal-focused characteristics appeared to hold greater value. Further to this, themes relating to availability of the SPC not previously mentioned in athlete studies (e.g., cost, willingness to travel) emerged as well as differences across the coach and parent populations within themes. One key example was reported within the interpersonal skills theme where parents would judge their selection of an SPC based on how they would feel in their company; a characteristic or criteria not reported by coaches.

Despite the advances in knowledge made from the data presented in study 1 using a qualitative thematic analysis approach, the overarching research aim was to elicit gatekeeper perceptions of SPCs. To achieve this, the intention of Study 2 was to employ a quantitative conjoint analysis to examine the salient SPC characteristics identified from Study 1, and to identify the relative value related to aspects of the descriptions. The purpose of the data being to increase awareness to the characteristics that SPCs may wish to develop to be more marketable to varying audiences who may seek their services (e.g., youth-sport coaches, parents) and to ultimately enhance their effectiveness as an SPC. In doing so, the authors acknowledge the tension that exists 
1 when using mixed-methods (cf. Sparkes, 2015) but progressed via the adoption of a pragmatic

2 stance to address the research question at a different level that in this case, required a shift from epistemological purity (see McGannon \& Schweinbenz, 2011 for a full review).

\section{Study 2 - Method}

\section{Participants}

A total of 115 participants (youth-sport coaches: $N=51$; parents: $N=64$ ) with either athletes or children currently involved in sport took part in the study. The coaches (male $=40$, female $=11 ; M$ age $=37.32, S D=12.33$ ) represented a range of competitive levels, including; voluntary (foundation/grassroots; $N=25$ ), county/regional $(N=14)$, or professional/governing body (academy/youth national; $N=12$ ). Similarly, parents (male $=24$, female $=40 ; M$ age $=46.51$, $S D=5.55)$ reported that their child participated at a foundation/grassroots $(N=16)$, county/regional $(N=34)$, or professional/governing body (academy/youth national; $N=14$ ) level. Participants were only eligible for participation in the study if they had no previous exposure to SPCs.

\section{Instrumentation}

Demographic Measures. Participants were first asked to complete items relating to their gender, age and their status as either a coach or a parent. Those identifying as a parent were asked to respond in relation to their child's level of competition (e.g. grassroots, county/regional, or professional/governing body) and age. Coach participants completed items relating to the level at which they coach (e.g. volunteer, county/regional, or professional/governing body) and the age of the athletes with which they work.

SPC Profiles. The selected attributes for the study were generated within study 1 of this two-part study, and resulted in five characteristics to be investigated. These were (a) experience and training, defined as the volume of experience held by the SPC and indicated by their qualification or training status; (b) interpersonal skills, defined as the ability of the SPC to use his or her personality to develop a positive working relationship with athletes; (c) consultant reputation, defined as the extent to which the perceived effectiveness of the SPC is known; (d) consultancy focus, defined as 
1 the SPCs primary focus of their work; and (e) service nature, defined as the method by which the

2 SPC is employed ${ }^{1}$.

The aim of a conjoint analysis is to determine the most preferred levels of each variable that

4 is investigated, therefore the following levels were selected for use in this study: a) experience and

5 training (high or low), b) interpersonal skills (high or low), c) reputation (high or low), d)

6 consultancy focus (performance or well-being), and e) service nature (independent or

7 organizational). This technique asks respondents to make choices by trading off features against

8 each other meaning that choices are made in the same fashion as the consumer presumably does.

9 Conjoint analysis allows the researcher to determine both the relative importance and the most preferred level of each attribute, is more robust than previously employed rank order techniques,

11 and can then be used to predict individuals' future decisions. In keeping with the expectations for an 12 effective conjoint analysis (Woolway \& Harwood, 2015), the attributes were deemed to be 13 independent of each other, thus limiting the potential for them to overlap and be 'double-counted', 14 and the statements were deemed appropriate given their concise meaning. As such, a full-profile method was utilized for this study with the combination of all variables and levels resulted in 32 SPC profiles that formed the instrumentation for this study. Participants were asked to rate their preference for each of the profiles on an 11-point scale ranging from 0 (Very low preference) to 10 (Very high preference). Presenting participants with 32 profiles in one form has the potential to add complexity and overwhelm individuals; profiles were divided into and presented as four equal sections of eight profiles each.

\section{Procedure}

Having received ethical clearance from the lead author's institution, participant information

23 and guidance, demographic questions, and the practitioner profiles were entered into

24 SurveyMonkey (www.surveymonkey.com). Participants were recruited via a combination of

25 approaches that included: contacts of the research team, social media, snowballing. Once they

\footnotetext{
${ }^{1}$ Information is available on request from the lead author in the form of supplementary figures relating to the information presented to participants about the five characteristics.
} 
1 volunteered their consent to take part, participants completed the demographic questions relating to

2 age, gender, and coach/parent level. Next, each SPC attribute was defined (e.g., experience and

3 training) alongside the choice of levels (e.g., high/low). Participants were then asked to rate their

4 preference for each of the 32 practitioner profiles on an 11-point scale.

\section{Data Analysis}

Data were downloaded into SPSS 23.0.0 and checked for any missing or incorrect responses prior to a conjoint analysis being conducted on individuals' rating data. Conjoint analysis produces utility (part-worth) scores and relative importance scores. Utilities (part-worth) provide a quantitative representation of the preference for each level of an attribute, and are expressed in a common unit, allowing for the addition of scores to produce the total utility of any given

combination. Following the conjoint analysis, Multivariate Analyses of Variance (MANOVA) were conducted to analyze the subgroup differences in terms of gender (male/female), and level of competition (coaches; volunteer/ county/ professional; parents; grassroots/ county/ professional).

\section{Results}

Conjoint analysis indicated that the most preferred SPC was one who had high levels of experience and training, high interpersonal skills, whose reputation was known, a consultancy focus on performance, and who worked independently of an organization. The relative importance ratings indicate that interpersonal skills (42\%) carried the most influence over participants' judgements, followed by experience and training (28\%), reputation (13\%), consultancy focus (9\%), and service nature (8\%).

Post-hoc MANOVA were conducted on the resulting utility (part-worth) scores to determine if there were any differences between subgroups in relation to their status as a coach or parent, their gender, and the level at which they coach/their child competes. Coach respondents rated SPCs with high experience and training significantly $(p<.01)$ higher than the parent sample (1.395 vs. 0.950; respectively). An additional significant $(\mathrm{p}<.01)$ finding between the two groups occurred in the consultancy focus attribute where coaches preferred an SPC who focused on performance, whereas 
1 parents preferred a focus on well-being ( 0.175 vs. -0.113; respectively). This latter finding was

2 again evident between male and female participants. The male sample significantly $(p<0.05)$

3 preferred an SPC who focused on performance, with the female group preferring one who focused

4 on well-being ( 0.148 vs -0.148 respectively for performance). These groups significantly $(p<.05)$

5 differed on their ratings for the consultants' service nature with male respondents preferring an SPC

6 who worked within an organization. The female sample preferred an SPC to work individually for

7 an organization (0.048 vs -0.092 respectively for organizational service nature).

After analyzing participant data by the level at which they coach/their child competes, one

9 significant difference $(p<.05)$ was evident. Volunteer coaches rated SPCs whose reputation was

10 known significantly higher than county/regional level coaches ( 0.619 vs 0.179 respectively). No

11 significant differences existed between other groups $(p<0.05)$.

\section{Discussion - Study 2}

The present study was designed to enhance understanding of youth-sport coach and parent preferences for SPC attributes with specific respect to sport psychology services. Interpersonal skills were identified as the most preferred SPC attribute, followed by experience and training, reputation, consultancy focus, and service nature. Such an outcome highlights the importance of interpersonal skills within the SPC domain and reflects the perceptions of others who seek, and experience successful support in alternative counselling-based professions (Pope, 1996). The combination of interpersonal skills and experience and training collectively accounted for more than $70 \%$ of the influence on consumer preferences across all participant groups in the study. The consistency, and degree to which importance was placed upon interpersonal skills unequivocally strengthen the recent calls for the development of this key personal competency within professional training programs (see Harwood, 2016).

Although professional titles were not explicitly referred to, participants were seemingly able to acknowledge the importance of training routes and experience. However, it would be irresponsible to assume that all participants were aware to what the appropriate training routes are 
1 to protected titles, and that potential service consumers are educated about the role, benefits, and

2 preferred characteristics of SPCs. Organizations with a responsibility for the governance of sport

3 psychology qualifications may benefit the field by providing appropriate information for potential

4 service users to enhance confidence regarding the profession. This is especially the case given the

5 upsurge in competing professions (e.g., life skills coaching) where individuals may be unaware of

6 the nuances between the varying professions that offer psychology-oriented services in the sporting

7 arena (Nasar \& Devlin, 2011). In fact, this very point reflects some interesting work in the field of

8 late where greater awareness, both within, and external to the profession, is advocated to what the

9 role of an SPC is (see Winter \& Collins, 2015a), and more poignantly to the importance of ensuring

10 that the approaches advocated and utilized within the profession have a sound evidence-based

11 underpinning (e.g., Winter \& Collins, 2015b). Excellent examples of this are the recent studies that

12 have examined the development, and usage of observation within applied sport psychology from

13 the perspective of experienced and trainee practitioners (e.g., Holder \& Winter, 2017; Martin,

14 Winter, \& Holder in press). To expand, observation has long been used as an assessment,

evaluation, and monitoring strategy by SPCs despite there being a lack of research, and subsequent guidance for training programs specific to the sport psychology domain. This commentary clearly

17 indicates that SPCs, be they trainees, or fully qualified, require a broad knowledge base, an expansive skillset and varying experiences to be able to respond to the increasing demands that sporting organizations and contexts place upon them. As SPCs are being challenged to be "more things to more people” it becomes essential for professional development and training systems to provide an appropriate quality assured, and well-regulated system of training.

\section{General Discussion}

The purpose of this research was to explore youth-sport coach and parent perceptions of

24 SPCs. To that end, Study 1 employed a qualitative thematic analysis where coaches and parents reported a common perception of SPCs in that they have an influence on athletic performance, 
1 standard. Although a performance focus was evident, further examination of the data suggested

2 parental perceptions of SPCs to be more focused towards general athlete development and well-

3 being. Study 2 built on the findings of Study 1 using a quantitative conjoint analysis to determine

4 the relative importance of the SPC characteristics with the findings of the work highlighting the

5 demand for SPCs with effective and high level interpersonal skills.

With the overall findings in mind, it would be appropriate to suggest that when neophytes

7 enter qualification pathways, a rigid appraisal of their interpersonal skills is conducted to establish

8 the extent to which they need to focus on developing such qualities early in the training process.

9 The same, of course, could also be levelled at more experienced SPCs who engage in continual reflection of their consulting effectiveness and engagement with client groups. Acknowledging the

11 broader issues associated with training programs and more specifically, competency development, organizations responsible for the development and provision of training routes may wish to utilize a model akin to that advocated by Miller (1990) for healthcare professions, to enable SPCs to progress from novice, to expert, in terms of knowledge application (Rønnestad \& Skovholt, 2003). Specifically, competence development progresses via the possession of knowledge (know), the interpretation of, and being able to apply the knowledge (know-how), demonstrating the application of knowledge (shows how), and finally applying the knowledge in 'real-world' (does). Within the context of interpersonal skill development, many neophytes are likely to enter a training programme with a knowledge to what the essential interpersonal skills are for working with a client (i.e., know), yet be unaware, or would not have been asked to consider, how the skills might be employed, for example, with a client in a high-performance environment when they are performing poorly (i.e.,

22 know-how). Undoubtedly, the key implication here is for professional associations responsible for developing training routes (and post-accreditation development) to mandate specific skills training as part of their qualifications given that such skills are now consistently being identified as preferred characteristics by those either seeking the services of an SPC for themselves, or for those for whom they are responsible. 
The nuanced findings around consultancy focus also bear some thought with respect to how

2 practitioners, both neophyte and experienced, may tailor their rapport building with parents and coaches. Whilst youth-sport coaches preferred a performance enhancement focus, parents ascribed greater importance to services favouring the well-being and personal development of their child.

5 This was also the case for females in the sample, the majority of whom were mothers (i.e., as

6 opposed to coaches). Although this factor was of less relative importance to other characteristics, it

7 offers implications not only for the ways that practitioners present themselves in general, but also

8 how they navigate potential philosophical differences between mothers and fathers in the family

9 dynamic. Indeed, a limitation of the current study is that it investigated those gatekeepers who may

10 be prospective consumers as opposed to those who have had extensive experience with sport

11 psychology consultants. Given the lack of experience with SPCs, it is fair to assume that detailed

12 perceptions to the role, and benefits of such individuals held by the participants could be limited.

13 However, given the richness of data that emerged from the interviews, coupled with the support for

14 themes presented in previous work and the emergence of new insights, the limitation may not be as dramatic as initially thought. Future work to compare data to individuals with more extensive experience with SPCs would certainly provide clarity here. Notwithstanding this, a further area for work would be to understand the hiring experiences and decisions of those managerial staff with direct organizational responsibility for employing sport psychologists (Hings, Wagstaff, Thelwell, Gilmore, \& Anderson, 2017; Larner, Wagstaff, Thelwell, \& Corbett, 2017). This current work could also be intimately extended to in-depth reflections of practitioners who have been hired by parents, aligned with reflections of parents who have employed practitioners to work with their child. Such research may also scrutinize views around independent versus organizationallyemployed practitioners as females (the majority of whom were parents) favoured an independent consultant over one provided through an organization. 
1 of an SPC, the benefits that an SPC could have on their athlete/child, and the characteristics that are

2 most salient to influence judgments on preference and likelihood to seek consultant services on

3 behalf of their athlete/child. Not only do the findings from Study 1 provide useful indicators of how

$4 \quad$ SPCs are viewed in terms of their role and benefit to client groups, but it also enabled a more

5 detailed insight to the characteristics that key gatekeepers seek in SPCs to take place in Study 2. As

6 such, from 32 differing practitioner profiles, the study revealed that an SPC who had high

7 interpersonal skills, an elevated level of experience and training, and a known reputation to be

8 preferred by all coach and parent participants. Such findings reinforce the importance of ensuring

9 that consumers are appropriately educated on the role and benefits of SPCs, and for training programmes to ensure that opportunities to demonstrate the application of interpersonal skills are available. We hope that the implications of these findings assist the ongoing professional development and promotion of the field of applied sport psychology.

\section{References}

Braun, V., \& Clarke, V. (2006). Using thematic analysis in psychology. Qualitative Research in Psychology, 3, 77-101.

Cotterill, S., \& Symes, R. (2014). Integrating social media and new technologies into your practice as a sport psychology consultant. Sport and Exercise Psychology Review, 10, 55-64.

Eubank, M. (2016). Trainee learning experiences for the demonstration of practitioner competence: A commentary on the commentary. Sport and Exercise Psychology Review, 12, 84-87.

Hamberger, M., \& Iso-Aloha, S.P. (2006). Factors affecting athletes’ attitudes toward sport psychology consultants. Journal of Contemporary Athletics, 2, 57-77.

Harwood, C.G. (2016). Doing Sport Psychology? Critical Reflections of a Scientist-Practitioner. In M. Raab, P. Wylleman, R. Seiler, A-M. Elbe, \& A. Hatzigeorgiadis, (Eds.), Sport and Exercise Psychology Research: From Theory to Practice (pp. 229-250). London; Elsevier. Harwood, C.G., \& Knight, C.J. (2015). Parenting in youth sport: A position paper on parenting expertise. Psychology of Sport and Exercise, 16, 24-35. 
1 Heaney, C. (2013). Keeping sport and exercise scientists 'appy' - online and mobile technologies in sport and exercise science. The Sport and Exercise Scientist, 37, 14-15.

Hings, R.F., Wagstaff, C.R.D., Thelwell, R.C., Gilmore, S., \& Anderson, V. (2017). Emotional labor and professional practice in sports medicine and science. Scandinavian Journal of Medicine and Science in Sports. doi: 10.1111/sms.12941

Holder, T., \& Winter, S. (2017). Experienced practitioners use of observation in applied sport psychology. Sport, Exercise, and Performance Psychology, 6, 6-19. doi:10.1037/spy0000072

Keegan, R.J., Harwood, C.G., Spray, C.M., \& Lavallee, D. (2014). A qualitative investigation of the motivational climate in elite sport. Psychology of Sport and Exercise, 15, 97-107. doi.org/10.1016/j.psychsport.2013.10.006

Knight, C., Berrow, S.R. \& Harwood, C.G. (2017). Parenting in sport. Current Opinion in Psychology, 16, 93-97. doi.org/10.1016/j.copsyc.2017.03.011

Larner, R.J., Wagstaff, C.R.D., Thelwell, R.C., \& Corbett, J. (2017). A multistudy examination of organizational stressors, emotional labor, burnout, and turnover in sport organizations. Scandinavian Journal of Medicine and Science in Sports. doi: 10.1111/sms.12833

Lovell, G.P., Parker, J.K., Brady, A., Cotterill, S.T., \& Howatson, G. (2011). Looking the part: Female sports psychologists' body mass index and dress influences athletes' perceptions of their potential effectiveness. The Sport Psychologist, 25, 82-93.

Lubker, J.R., Visek, A.J., Watson, J.C., \& Singpurwalla, D. (2012). Athletes’ preferred characteristics and qualifications of sport psychology practitioners: A consumer market analysis. Journal of Applied Sport Psychology, 24, 465-480.

Lubker, J.R., Watson, J.C., Visek, A.J., \& Geer, J.R. (2005). Physical appearance and the perceived effectiveness of performance enhancement consultants. The Sport Psychologist, 19, 446458.

Maniar, S D., Curry, L.A., Sommers-Flanagan, J., \& Walsh, J.A. (2001). Student-athlete 
preferences in seeking help when confronted with sport performance problems. The Sport Psychologist, 15, 205-223.

Martin, E.A., Winter, S., \& Holder, T. (in press). An exploration of trainee practitioners’ experiences when using observation. The Sport Psychologist. DOI: http://dx.doi.org/10.1123/tsp.2016-0019

McCarthy, P. \& Giges, B. (2017). Helping coaches meet their psychological needs. In R. Thelwell, C. Harwood, \& I. Greenlees, (eds.), The Psychology of Sports Coaching: Research and Practice (pp. 101-113). London, UK: Routledge.

McGannon, K.R. \& Schweinbenz, A.N. (2011). Traversing the qualitative-quantitative divide using mixed methods: Some reflections and reconciliations for sport and exercise psychology. Qualitative Research in Sport, Exercise and Health, 3, 367-381.

Miller, G.E. (1990). The assessment of clinical skills/competence/performance. Academic Medicine, 65, S63-67.

Morris, T., Alfermann, D., Lintunen, T., \& Hall, H. (2003). Training and selection of sport psychologists: An international review. International Journal of Sport and Exercise Psychology, 1, 139-154.

Nasar, J.L., \& Devlin, A.S. (2011). Impressions of psychotherapist’s offices. Journal of Counseling Psychology, 58, 310-320. doi:10.1037/a0023887

Ponnusamy, V., \& Grove, J.R. (2014). Sport psychology service provision: Preferences for consultant characteristics and mode of delivery among elite Malaysian athletes. Journal of Sports Science \& Medicine, 13(3), 638-644.

Pope,V.T. (1996). Stable personality characteristics of effective counselors: The Counselor Characteristic Inventory. Dissertation Abstracts International, 57, 1503.

Rønnestad, M.H., \& Skovholt, T.M. (2003). The journey of the counsellor and therapist: Research findings and perspectives of professional development. Journal of Career Development, 30, 5-44. 
1 Rynne, S., Mallett, C., \& Rabjohns, M. (2017). High performance coaching: demands and development. In R. Thelwell, C. Harwood \& I. Greenlees (eds.), The Psychology of Sports Coaching: Research and Practice (pp. 114-127). London, UK: Routledge.

Schinke, R.J., McGannon, K.R., Battochio, R.C., \& Wells, G.D. (2013). Acculturation in elite sport: A thematic analysis of immigrant athletes and coaches. Journal of Sports Sciences, 31, 1676-1686. doi.org/10.1080.02640414.2013.794949.

Smith, B., \& McGannon, K.R. (2017). Developing rigor in qualitative research: Problems and opportunities within sport and exercise psychology. International Review of Sport and Exercise Psychology. doi.org/10.1080/1750984X.2017.1317357.

Sparkes, A. C. (2015). Developing mixed methods research in sport and exercise psychology: Critical reflections on five points of controversy. Psychology of Sport and Exercise, 16, 4959.

Taylor, J. (1994). Examining the boundaries of sport science and psychology training practitioners in applied sport psychology: Title usage and area of competence. Journal of Applied Sport Psychology, 6, 185-195.

Van Raalte, J.L., Brewer, D.D., Matheson, H., \& Brewer, B.W. (1996). British athletes’ perceptions of sport and mental health practitioners. Journal of Applied Sport Psychology, 8, 102-108. doi.org/10.1080/10413209608406311

Visek, A.J., Harris, B.S., \& Blom, J.C. (2009). Doing sport psychology: A youth sport consulting model for practitioners. The Sport Psychologist, 23, 271-291.

Winter, S., \& Collins, D. (2015a). Why do we do, what we do? Journal of Applied Sport Psychology, 27, 35-51. doi:10.1080/10413200.2014.941511.

Winter, S., \& Collins, D. (2015b). Where is the evidence in our sport psychology practice? A UK perspective on the underpinnings of action. Professional Psychology: Research and Practice, 46, 175-182. doi:10/1037/pro0000014 
1 Woolway, T., \& Harwood, C.G. (2015). Do titles matter in sport psychology? Performer attitudes toward professional titles and the effect of a brief intervention. The Sport Psychologist, 29, 171-182.

Wrisberg, C.A., Loberg, L.A., Simpson, D., Withycombe, J.L., \& Reed, A. (2010). An exploratory investigation of NCAA Division-I coaches' support of sport psychology consultants and willingness to seek mental training services. The Sport Psychologist, 24, 489-50.

Zakrajsek, R., Fisher, L., \& Martin, S. (2016). Certified athletic trainers' understanding and use of sport psychology in their practice. Journal of Applied Sport Psychology. doi.org/10.1080/10413200.2016.1231722

Zakrajsek, R., Martin, S.B., \& Wrisberg, C.A. (2016). National collegiate athletic association Division 1 certified athletic trainers’ perceptions of the benefits of sport psychology services. Journal of Athletic Training, 51, 398-405. doi:10.4085/1062-6050-51.5.13

Zakrajsek, R. A., Martin, S. B., \& Zizzi, S. J. (2011). American high school football coaches' attitudes toward sport psychology consultation and intentions to use sport psychology services. International Journal of Sports Science \& Coaching, 6, 461-478.

Zakrajsek, R, Steinfeldt, J.A., Bodey, K.J., Martin, S.B., \& Zizzi, S. (2013). NCAA Division 1 coaches’ perceptions and preferred use of sport psychology services: A qualitative perspective. The Sport Psychologist, 27, 258-268. 
2 Figure 1. Understanding of the SPC role (a frequency analysis is provided in the first column to

3 illustrate youth-sport coach responses and in the second column for parent responses).

$4 \quad$ Figure 2. Perceived benefits of seeking the services of an SPC (a frequency analysis is provided in

5 the first column to illustrate youth-sport coach responses and in the second column for parent

6 responses).

7 Figure 3. Characteristics of an SPC that would influence judgment to seek services (a frequency

8 analysis is provided in the first column to illustrate youth-sport coach responses and in the second

9 column for parent responses).

10 Figure 4. The part-worth utility values and relative importance for parent and coach subgroups.

11 Figure 5. The part-worth utility values and relative importance for male and female subgroups. 
Perceptions of SPCs 32

\begin{tabular}{|c|c|c|c|c|}
\hline 8 & 6 & Help athletes become successful & & \multirow{50}{*}{ SPC role } \\
\hline 5 & 2 & Help athletes fulfil their potential & & \\
\hline 5 & 1 & Optimize athletic performance & & \\
\hline 4 & 4 & To enhance athlete confidence & & \\
\hline 3 & 2 & Develop coping mechanisms & & \\
\hline 3 & 2 & To develop the resilience and toughness of athletes & & \\
\hline 3 & 2 & To benefit recovery from setbacks & & \\
\hline 3 & 3 & Improve psychological aspects of performance & Athlete performance & \\
\hline 3 & - & To ensure that athletes prepare and review performance & & \\
\hline 2 & - & Enable improved decision-making during performance & & \\
\hline 2 & 2 & To enhance emotion management before, during and post-performance & & \\
\hline 2 & 5 & To help athletes manage pressure in performance & & \\
\hline 2 & - & To assess athletes for intervention work & & \\
\hline 1 & 1 & To help athletes understand situations before they happen & & \\
\hline 1 & 2 & To help athletes set goals and know how to achieve them & & \\
\hline$\overline{9}$ & $\frac{3}{5}$ & $\begin{array}{l}\text { To help them address problems } \\
\text { Improve athlete understanding of mental skills benefits }\end{array}$ & \multirow{11}{*}{$\begin{array}{l}\text { Athlete development and well- } \\
\text { being }\end{array}$} & \\
\hline 9 & 5 & Help athletes understand demands of elite sport & & \\
\hline 5 & 3 & Enable athletes to see the bigger picture & & \\
\hline 4 & 1 & To aid transition of athletes across levels & & \\
\hline 3 & - & To refer to alternative specialists when necessary & & \\
\hline 2 & 2 & To understand their sport in the context of other life demands & & \\
\hline 2 & 3 & To monitor athlete well-being & & \\
\hline - & 2 & Enable athletes to disclose issues & & \\
\hline - & 3 & Ensure welfare is monitored & & \\
\hline - & 3 & Provide guidance on alternative careers & & \\
\hline - & 2 & To monitor workloads and potential for burnout & & \\
\hline 6 & $\frac{2}{3}$ & Help keep coaches confident and focused & \multirow{11}{*}{ Coach support } & \\
\hline 6 & - & Be a point of contact for coaches & & \\
\hline 5 & - & Provide feedback on athletes in case meetings & & \\
\hline 5 & - & To help develop coach toughness and resilience & & \\
\hline 5 & - & Develop awareness to coach pressure and stress & & \\
\hline 4 & - & Develop coach preparation & & \\
\hline 4 & 2 & Help coaches understand demands on athletes & & \\
\hline 4 & - & Support for organizational demands on coaches & & \\
\hline 3 & - & Review coach performance & & \\
\hline 2 & 3 & Observation of behaviors during training and competition & & \\
\hline 1 & - & Mediating issues & & \\
\hline 9 & - & Help coaches integrate psychology into training & \multirow{7}{*}{ Coach development } & \\
\hline 8 & 2 & Contribute to session development & & \\
\hline 7 & - & Provide feedback to coaches on communication methods & & \\
\hline 6 & - & Help coaches reflect on delivery styles & & \\
\hline 6 & - & Review the coaching environments & & \\
\hline 5 & 3 & Develop leadership skills for varying athletes & & \\
\hline 5 & - & Deliver coach-education workshops & & \\
\hline 6 & 5 & To provide parental sessions & \multirow{4}{*}{ Support other groups } & \\
\hline 5 & - & Facilitate team support meetings & & \\
\hline 2 & 6 & To raise awareness of sport psychology to parents & & \\
\hline- & 5 & Provide feedback to parents on communication methods & & \\
\hline 5 & - & Develop psychology support across the full programme & Psychology education & \\
\hline 5 & - & Ensure a consistent psychology curriculum in the club & & \\
\hline 11 & 10 & Provide individual support & Individual support & \multirow{7}{*}{ Delivery mode } \\
\hline 8 & 6 & Work with individuals over a period of time & & \\
\hline 11 & 5 & Deliver group sessions on key themes & & \\
\hline 11 & 6 & Present workshops & Group/education sessions & \\
\hline 4 & 1 & Work with sub-groups where appropriate & & \\
\hline 7 & 2 & Deliver the psychology in the [sporting environment] & \multirow[b]{2}{*}{ Practical sessions } & \\
\hline $\begin{array}{l}5 \\
3\end{array}$ & - & $\begin{array}{l}\text { Lead the [practical] session with a psychology focus } \\
\text { Show how the psychology links with the training }\end{array}$ & & \\
\hline 4 & 3 & Available at all times & \multirow{2}{*}{ Regular contact } & \multirow{15}{*}{ Availability } \\
\hline 3 & 1 & Contact once a week & & \\
\hline 11 & 8 & When [athlete] requires them & \multirow{3}{*}{ Partial contact } & \\
\hline 8 & 4 & Whenever [coach] thinks that the athlete needs them & & \\
\hline- & 3 & Whenever [parent] thinks that the athlete needs them & & \\
\hline 11 & 11 & Present at training sessions & \multirow{3}{*}{ Training } & \\
\hline 8 & 4 & Be around the training environment & & \\
\hline 6 & 2 & Be able to integrate with athletes during training & & \\
\hline 10 & 5 & Important to be present during competition, but not a distraction & Competition & \\
\hline 6 & 1 & Be visible at competition so it has an impact & & \\
\hline $\begin{array}{ll}11 \\
4\end{array}$ & $\begin{array}{l}7 \\
2\end{array}$ & $\begin{array}{l}\text { Meet with [athletes / coaches / others] away from sport environment } \\
\text { Have meetings in the [club] }\end{array}$ & Neutral & \\
\hline 9 & 4 & Important to have their details & & \\
\hline 4 & 4 & Consult via Skype & E.support & \\
\hline 4 & 4 & Use emails for feedback & & \\
\hline 3 & 1 & Use text messages and other e.formats & & \\
\hline
\end{tabular}


Perceptions of SPCs 33

\begin{tabular}{|c|c|c|c|c|}
\hline 11 & 8 & Positive attitude & & \multirow{48}{*}{$\begin{array}{l}\text { Enhanced } \\
\text { psychological strength }\end{array}$} \\
\hline 10 & 6 & Confident thoughts and behaviors & & \\
\hline 10 & 6 & Positive mindset & Enhanced confidence & \\
\hline 5 & - & Confident to talk to others such as coaches / specialists & & \\
\hline 4 & 2 & Knowing what they have over others & & \\
\hline 10 & 6 & Better ability to cope with sporting demands & \multirow{11}{*}{ Toughness and resilience } & \\
\hline 10 & 1 & Knowing others are competing for your place & & \\
\hline 9 & 6 & Managing poor performance and slumps & & \\
\hline 9 & 5 & Coping with pressure & & \\
\hline 5 & 3 & Awareness to expectations of self and others & & \\
\hline 5 & 1 & Awareness of additional demands such as travel & & \\
\hline 5 & - & Develop skills to see things as a challenge & & \\
\hline 4 & 2 & Overcoming doubt and capability worry & & \\
\hline 2 & - & Enhanced awareness to performance review & & \\
\hline - & 6 & Not feeling guilt about success for parents & & \\
\hline- & 5 & Management of expectations & & \\
\hline 8 & 6 & Enhanced ability to focus on what is needed & \multirow{3}{*}{ Enhanced focus } & \\
\hline 7 & 2 & Setting realistic and appropriate goals & & \\
\hline 2 & - & Shutting out the things that disrupt focus & & \\
\hline 8 & 4 & Developing string routines and preparation strategies & \multirow{5}{*}{ Enhanced preparation } & \\
\hline 7 & 4 & Knowing what their preparation is & & \\
\hline 4 & 4 & Not having to follow everyone else in what they do & & \\
\hline 4 & - & Developing an individualized routine & & \\
\hline 1 & - & Having flexibility in their routine & & \\
\hline 9 & 6 & Enhanced ability to react correctly in-performance & \multirow{6}{*}{ In-performance awareness } & \\
\hline 7 & 2 & Continue to focus on the right decisions & & \\
\hline 6 & 2 & Not getting caught up in the situation & & \\
\hline 5 & - & Critical moment awareness & & \\
\hline 3 & 3 & Using the key strategies during performance & & \\
\hline 2 & - & Keeping to the processes & & \\
\hline 5 & 4 & Understanding to the demands of an elite athlete lifestyle & \multirow{5}{*}{ Sporting toughness } & \\
\hline 4 & 2 & Preparation to make sacrifices & & \\
\hline 3 & - & Being prepared to do the right things all the time & & \\
\hline 2 & - & Ensuring the standards are understood and maintained & & \\
\hline 2 & 3 & Awareness of 'living on the line' with injuries & & \\
\hline 4 & 6 & Increased awareness to how and why they behave like they do & \multirow{7}{*}{ Enhanced self-awareness } & \\
\hline 3 & 5 & Better awareness to reactions to situations & & \\
\hline 1 & - & Understanding preparedness to adhere to requirements & & \\
\hline - & 6 & To leave the sport behind at the door & & \\
\hline - & 6 & To still be a person but not lose focus & & \\
\hline - & 7 & Reinforce importance of enjoyment & & \\
\hline - & 2 & Better awareness of things outside of [sport] & & \\
\hline 4 & 3 & Knowing why others behave like they do & \multirow{6}{*}{ Understanding of others } & \\
\hline 4 & - & Understand why coaches talk like they do & & \\
\hline 3 & 1 & Awareness of opponent behaviour & & \\
\hline 3 & 2 & Awareness of teammates behaviour & & \\
\hline 2 & 4 & Understanding parental influence & & \\
\hline- & 4 & Understanding sibling relationships & & \\
\hline 8 & 4 & Understanding competition demands & \multirow{3}{*}{$\begin{array}{l}\text { Competition performance } \\
\text { demands }\end{array}$} & \\
\hline 6 & 1 & Awareness of 'other factors' that require management during competition & & \\
\hline 3 & 2 & Planning for competition eventualities & & \\
\hline 6 & 4 & Attitudes and expectations & & \\
\hline 5 & 4 & Making sure that the right things are done & & \\
\hline 5 & 1 & Training as they want to perform & Training behaviour and & \\
\hline 3 & - & Getting into good habits & expectations & \\
\hline 2 & 2 & Understanding the importance of quality training & & \\
\hline- & 3 & Encourage appropriate behaviors and standards & & \\
\hline 4 & 6 & How you are perceived away from [the sport] & & Elite standard \\
\hline 2 & 5 & Other [non-sport] demands that are placed on athletes & Non-sport awareness & awareness \\
\hline 1 & 3 & Consideration if things do not work out & & \\
\hline 5 & - & Where are [athlete] in terms of the organization & Organizational expectations & \\
\hline 5 & - & How many others would want to [perform for] the organization & & \\
\hline 4 & - & Remembering who you are representing & & \\
\hline 8 & 7 & Making the most of their opportunities & & \\
\hline 7 & 6 & Giving everything they can to develop themselves & Personal limits and growth & \\
\hline 6 & 1 & Not being 'lazy' and trying to see the bigger picture & potential & \\
\hline 2 & 2 & Every session is an opportunity to learn & & \\
\hline 7 & 2 & Understanding demands of elite sport & Professional attitude & \\
\hline 3 & - & Awareness to how all areas operate together & development & \\
\hline 3 & - & Cannot cut corners & & \\
\hline
\end{tabular}


Perceptions of SPCs 34

\begin{tabular}{|c|c|c|c|c|}
\hline $\begin{array}{l}4 \\
3 \\
2 \\
-\end{array}$ & $\begin{array}{l}- \\
- \\
3 \\
-\end{array}$ & $\begin{array}{l}\text { Previous personal experiences as an athlete } \\
\text { Previous personal experiences as a coach } \\
\text { Knowledge of the consultant } \\
\text { Having previously employed the consultant for [child] }\end{array}$ & $\begin{array}{l}\text { Previous experiences with } \\
\text { consultant }\end{array}$ & \multirow{5}{*}{ Reputation } \\
\hline 3 & 3 & Comments from other coaches who have worked with [the consultant] & & \\
\hline 2 & $\begin{array}{l}3 \\
3\end{array}$ & $\begin{array}{l}\text { Comments from other coaches who are aware of [the consultant's] work } \\
\text { Support judgment of the coach }\end{array}$ & Other coaches feedback & \\
\hline $\begin{array}{l}4 \\
3 \\
2 \\
-\end{array}$ & $\begin{array}{l}5 \\
2 \\
3 \\
4\end{array}$ & $\begin{array}{l}\text { Being recommended to use [the consultant] } \\
\text { Other people's testimonies of [the consultant] } \\
\text { Word of mouth } \\
\text { References }\end{array}$ & Recommendations & \\
\hline 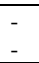 & $\begin{array}{l}6 \\
2\end{array}$ & $\begin{array}{l}\text { How they present themselves } \\
\text { How easy they are to find }\end{array}$ & Advertising & \\
\hline $\begin{array}{l}6 \\
4 \\
2\end{array}$ & $\begin{array}{l}2 \\
- \\
1\end{array}$ & $\begin{array}{l}\text { Must be fully qualified as a psychologist } \\
\text { Need to have a psychology qualification } \\
\text { Need to be professionally accredited }\end{array}$ & Professional accreditation & \multirow{3}{*}{ Qualification } \\
\hline $\begin{array}{l}3 \\
1\end{array}$ & - & $\begin{array}{l}\text { Should have a Masters degree at least } \\
\text { Need to have done a postgraduate degree }\end{array}$ & Postgraduate degree & \\
\hline 2 & 2 & Other performance-related qualifications & Other qualifications & \\
\hline $\begin{array}{l}5 \\
4 \\
4 \\
3 \\
3 \\
3 \\
3 \\
2 \\
1\end{array}$ & $\begin{array}{l}6 \\
- \\
5 \\
- \\
- \\
6 \\
5 \\
- \\
-\end{array}$ & $\begin{array}{l}\text { Knowledge of the sport } \\
\text { Knowing the intricacies of the sport and the organization } \\
\text { Ability to put psychology speak into sport language } \\
\text { Knowing how support teams operate } \\
\text { Knowing the environment to work in } \\
\text { Understanding the sporting demands } \\
\text { Knowing the athlete demands for the sport } \\
\text { Awareness to funding and general finance issues } \\
\text { Understanding athlete access issues }\end{array}$ & Sporting knowledge & \multirow[t]{2}{*}{ Knowledge } \\
\hline $\begin{array}{l}4 \\
2 \\
1 \\
- \\
-\end{array}$ & $\begin{array}{l}5 \\
- \\
- \\
5 \\
4\end{array}$ & $\begin{array}{l}\text { Knowing how to communicate with [the population] to be worked with } \\
\text { Knowing the challenge that [the population] are faced with within the sport } \\
\text { Knowing how [the population] are expected to fit in with others in the organization } \\
\text { Understanding adolescents and relationships with parents / within families } \\
\text { Understanding parental worries and concerns }\end{array}$ & Population knowledge & \\
\hline $\begin{array}{l}6 \\
2 \\
1 \\
- \\
-\end{array}$ & $\begin{array}{l}6 \\
4 \\
- \\
7 \\
2\end{array}$ & $\begin{array}{l}\text { Volume of experience they have as a consultant in sport } \\
\text { What sports they have worked in } \\
\text { What groups they have worked with } \\
\text { Expert in their field } \\
\text { Awareness of broader psychological issues }\end{array}$ & Consultant - general & \multirow{6}{*}{ Experience } \\
\hline $\begin{array}{l}5 \\
4 \\
1 \\
\end{array}$ & $\begin{array}{l}4 \\
- \\
-\end{array}$ & $\begin{array}{l}\text { Whether they have worked in [the sport] } \\
\text { Why they want to work in the sport } \\
\text { Have they just done bits and pieces or are they really experienced }\end{array}$ & Consultant - sport & \\
\hline $\begin{array}{l}1 \\
3 \\
3\end{array}$ & $\begin{array}{l}4 \\
-\end{array}$ & $\begin{array}{l}\text { Have they worked with [the population] category before } \\
\text { How will they work with [the population] if they were to be recruited }\end{array}$ & Consultant - population & \\
\hline $\begin{array}{l}5 \\
2\end{array}$ & $\begin{array}{l}4 \\
2\end{array}$ & $\begin{array}{l}\text { What experience do they have as a performer in [sport] } \\
\text { Have they excelled in [the sport] }\end{array}$ & Performance & \\
\hline $\begin{array}{l}3 \\
1\end{array}$ & - & $\begin{array}{l}\text { Have they coached in [the sport] before } \\
\text { Potential to cross boundaries }\end{array}$ & Coach & \\
\hline- & 3 & Are they a parent and do they know how parents think & Parent & \\
\hline 6 & 4 & Non-judgemental communication & \multirow{6}{*}{ Communication } & \multirow{21}{*}{ Interpersonal skills } \\
\hline 5 & 3 & Athlete friendly language & & \\
\hline 4 & 3 & Emphasis on support and performance awareness & & \\
\hline 2 & - & Understanding of appropriate language for use & & \\
\hline- & 7 & Whether I would feel happy in their company & & \\
\hline- & $\begin{array}{l}3 \\
2\end{array}$ & $\begin{array}{l}\text { Not seeing us as a threat } \\
\text { Open to feedback }\end{array}$ & & \\
\hline 11 & 10 & Approachable & \multirow{13}{*}{ Interpersonal style } & \\
\hline 11 & 8 & Personable & & \\
\hline 10 & 6 & Able to listen & & \\
\hline 9 & 11 & Trustworthy & & \\
\hline 8 & 4 & Timeliness & & \\
\hline 8 & 6 & Respected & & \\
\hline 7 & 3 & Empathetic & & \\
\hline 7 & 5 & Confident and assured & & \\
\hline 5 & - & Sense of humour & & \\
\hline 4 & 9 & Friendly & & \\
\hline 2 & 2 & Calm and clear & & \\
\hline 1 & 2 & Respectful & & \\
\hline 1 & - & $\begin{array}{l}\text { Treats athletes as individuals and people, not robots } \\
\text { Discretion }\end{array}$ & & \\
\hline 5 & 2 & Looking like part of the team & \multirow[b]{2}{*}{ Observable presentation } & \\
\hline 5 & 3 & $\begin{array}{l}\text { Professional appearance } \\
\text { Looking like they fit in }\end{array}$ & & \\
\hline 6 & - & Preparedness to work on a contract and be available for specific sessions & \multirow{3}{*}{ Contract } & \multirow{9}{*}{ Service nature } \\
\hline 6 & - & Regular contact to aid immersion into support team & & \\
\hline 5 & - & Guarantee of a certain number of hours per week, month or year & & \\
\hline 2 & 6 & Preparedness to be available when required as opposed to having regular contact & On-call & \\
\hline 3 & $\begin{array}{l}6 \\
2\end{array}$ & $\begin{array}{l}\text { Value for money } \\
\text { What is the cost verses benefit? }\end{array}$ & Cost & \\
\hline 3 & - & Willingness to travel to training and competitions & \multirow{4}{*}{ Travel } & \\
\hline 3 & - & Willingness to travel to meet athletes & & \\
\hline- & 4 & Distance to have to go to see consultant & & \\
\hline- & 2 & Preparedness to travel to us & & \\
\hline
\end{tabular}


Perceptions of SPCs 35

\begin{tabular}{|c|c|c|c|c|}
\hline \multirow[b]{2}{*}{ Attribute } & \multicolumn{2}{|r|}{ Coach } & \multicolumn{2}{|c|}{ Parent } \\
\hline & $\begin{array}{c}\text { Utilities } \\
\text { (Part-Worth) }\end{array}$ & $\begin{array}{c}\text { Relative Importance } \\
\text { Rankings }\end{array}$ & $\begin{array}{l}\text { Utilities } \\
\text { (Part- } \\
\text { Worth) }\end{array}$ & $\begin{array}{c}\text { Relative } \\
\text { Importance } \\
\text { Rankings }\end{array}$ \\
\hline $\begin{array}{l}\text { Experience and } \\
\text { training }\end{array}$ & & $33 \%$ & & $25 \%$ \\
\hline $\begin{array}{l}\text { High } \\
\text { Low }\end{array}$ & $\begin{array}{r}1.395^{*} \\
-1.395^{*}\end{array}$ & & $\begin{array}{r}.950^{*} \\
-.950^{*}\end{array}$ & \\
\hline $\begin{array}{l}\text { Interpersonal } \\
\text { skills }\end{array}$ & & $39 \%$ & & $45 \%$ \\
\hline $\begin{array}{l}\text { High } \\
\text { Low }\end{array}$ & $\begin{array}{r}1.605 \\
-1.605\end{array}$ & & $\begin{array}{r}1.835 \\
-1.835\end{array}$ & \\
\hline Reputation & & $12 \%$ & & $13 \%$ \\
\hline $\begin{array}{l}\text { Known } \\
\text { Unknown }\end{array}$ & $\begin{array}{r}.445 \\
-.445\end{array}$ & & $\begin{array}{l}.526 \\
-.526\end{array}$ & \\
\hline $\begin{array}{l}\text { Consultancy } \\
\text { focus }\end{array}$ & & $7 \%$ & & $10 \%$ \\
\hline $\begin{array}{l}\text { Performance } \\
\text { Well-being }\end{array}$ & $\begin{array}{r}.175^{*} \\
-.175^{*}\end{array}$ & & $\begin{array}{l}-.113^{*} \\
.113^{*}\end{array}$ & \\
\hline Service nature & & $9 \%$ & & $7 \%$ \\
\hline $\begin{array}{l}\text { Organization } \\
\text { Independent }\end{array}$ & $\begin{array}{r}.039 \\
-.039 \\
\end{array}$ & & $\begin{array}{r}-.056 \\
.056 \\
\end{array}$ & \\
\hline
\end{tabular}

Note. *difference: $\mathrm{p}<.05$. 
Perceptions of SPCs 36

\begin{tabular}{|c|c|c|c|c|}
\hline \multirow[b]{2}{*}{ Attribute } & \multicolumn{2}{|r|}{ Male } & \multicolumn{2}{|r|}{ Female } \\
\hline & $\begin{array}{c}\text { Utilities } \\
\text { (Part-Worth) }\end{array}$ & $\begin{array}{l}\text { Relative Importance } \\
\text { Rankings }\end{array}$ & $\begin{array}{c}\text { Utilities } \\
\text { (Part- } \\
\text { Worth) }\end{array}$ & $\begin{array}{c}\text { Relative Importance } \\
\text { Rankings }\end{array}$ \\
\hline $\begin{array}{l}\text { Experience and } \\
\text { training }\end{array}$ & & $32 \%$ & & $24 \%$ \\
\hline $\begin{array}{l}\text { High } \\
\text { Low }\end{array}$ & $\begin{array}{r}1.251 \\
-1.251\end{array}$ & & $\begin{array}{r}1.018 \\
-1.018\end{array}$ & \\
\hline $\begin{array}{l}\text { Interpersonal } \\
\text { skills }\end{array}$ & & $40 \%$ & & $46 \%$ \\
\hline $\begin{array}{l}\text { High } \\
\text { Low }\end{array}$ & $\begin{array}{r}1.627 \\
-1.627\end{array}$ & & $\begin{array}{r}1.865 \\
-1.865\end{array}$ & \\
\hline Reputation & & $13 \%$ & & $12 \%$ \\
\hline $\begin{array}{l}\text { Known } \\
\text { Unknown }\end{array}$ & $\begin{array}{r}.500 \\
-.500\end{array}$ & & $\begin{array}{l}.478 \\
-.478\end{array}$ & \\
\hline $\begin{array}{l}\text { Consultancy } \\
\text { focus }\end{array}$ & & $8 \%$ & & $10 \%$ \\
\hline $\begin{array}{l}\text { Performance } \\
\text { Well-being }\end{array}$ & $\begin{array}{r}.145^{*} \\
-.145^{*}\end{array}$ & & $\begin{array}{r}-.148^{*} \\
.148^{*}\end{array}$ & \\
\hline Service nature & & $8 \%$ & & $8 \%$ \\
\hline $\begin{array}{l}\text { Organization } \\
\text { Independent }\end{array}$ & $\begin{array}{r}.048 * \\
-.048 *\end{array}$ & & $\begin{array}{r}-.092 * \\
.092 *\end{array}$ & \\
\hline
\end{tabular}

Note. *difference: $\mathrm{p}<.05$. 